\title{
Predictors for intravenous immunoglobulin resistance and coronary artery lesions in Kawasaki disease
}

Tian Xie, Ying Wang, Songling Fu, Wei Wang, Chunhong Xie, Yiying Zhang and Fangqi Gong*

\begin{abstract}
Background: To assess the predictors for intravenous immunoglobulin (IVIG) resistance and coronary artery lesions (CALs) in Kawasaki disease (KD).

Methods: A total of $560 \mathrm{KD}$ patients were reviewed retrospectively, including 410 complete KD (cKD) and 150 incomplete KD (iKD) patients. The laboratory data were compared between the IVIG-resistant and IVIG-responsive groups, as well as between the coronary artery lesions (CALs+) and without coronary artery lesions (CALs-) groups.

Results: In the CKD patients, C-reactive protein (CRP) levels had a sensitivity of $65.52 \%$ and a specificity of $62.7 \%$ for predicting IVIG-resistance at a cutoff point of $>100 \mathrm{mg} / \mathrm{L}$. When albumin $<32 \mathrm{~g} / \mathrm{L}$, the sensitivity and specificity for predicting IVIG-resistance were 72 and 83.19\%, respectively. N-terminal pro-brain natriuretic peptide (NT-proBNP) levels had a sensitivity of $73.91 \%$ and a specificity of $76.43 \%$ for predicting IVIG-resistance at a cutoff point of $>1300 \mathrm{pg} / \mathrm{ml}$. Interleukin-6 levels had a sensitivity of $76.19 \%$ and a specificity of $61.59 \%$ at a cutoff value of $>45$ $\mathrm{pg} / \mathrm{ml}$. Erythrocyte sedimentation rate (ESR) levels had a sensitivity of $53.26 \%$ and a specificity of $64.14 \%$ for predicting CALs at a cutoff point of $>75 \mathrm{~mm} / \mathrm{h}$.

In the iKD patients, the sensitivity and specificity for predicting IVIG-resistance were 80 and $54.1 \%$ when hemoglobin $<110 \mathrm{~g} / \mathrm{L}$. When proportion of neutrophils $>70 \%$, the sensitivity and specificity for predicting IVIG-resistance were 68 and $66.94 \%$, respectively. ESR levels had a sensitivity of $70.83 \%$ and a specificity of $65.81 \%$ for predicting IVIG-resistance at a cutoff point of $>80 \mathrm{~mm} / \mathrm{h}$. NT-proBNP levels had a sensitivity of $78.57 \%$ and a specificity of $56.67 \%$ for predicting IVIG-resistance at a cutoff point of $>360 \mathrm{pg} / \mathrm{ml}$. Interleukin- 6 levels had a sensitivity of $70.59 \%$ and a specificity of 66 . $28 \%$ at a cutoff value of $>25 \mathrm{pg} / \mathrm{ml}$. Interleukin- 10 levels had a sensitivity of $64.71 \%$ and a specificity of $74.42 \%$ for predicting IVIG-resistance at a cutoff value of $>8 \mathrm{pg} / \mathrm{ml}$. ESR levels had a sensitivity of $61.82 \%$ and a specificity of $65.12 \%$ for predicting CALs at a cutoff point of $>75 \mathrm{~mm} / \mathrm{h}$.
\end{abstract}

Conclusions: The white blood cell count, proportion of neutrophils, hemoglobin, CRP, ESR, albumin, NT-proBNP, interleukin-6 and 10 may be effective predictors for IVIG resistance and CALs in KD patients.

Keywords: Kawasaki disease, Intravenous immunoglobulin, Coronary artery lesions

\footnotetext{
* Correspondence: gongfangqi@zju.edu.cn

Children's Hospital, Zhejiang University School of Medicine, No.57, Zhugan

Lane, Hangzhou 310003, People's Republic of China
} 


\section{Background}

Kawasaki disease (KD) is an acute, self-limited, systemic vasculitis that predominantly affects children younger than five years, and is the leading cause of acquired heart disease in children [1]. The pathogenesis of KD still remains unknown although nearly fifty years have passed since the first report by Tomisaku Kawasaki in 1967 [2]. Although intravenous immunoglobulin (IVIG) combined with aspirin were commonly adopted as the most important therapy protocol which could effectively decrease the incidence of coronary artery lesions (CALs), the high incidence of IVIG-resistant and CALs were reported in recent years [3-7]. Therefore, it is very important to predict IVIG-resistance and CALs in patients with KD. Scoring systems for predicting unresponsiveness to IVIG therapy [8, 9] and risk factors of CALs [3, 10-12] have been extensively studied. However, there is no consensus on the risk factors of IVIG-resistance and CALs because of low sensitivity and specificity in those studies, which may be attributed to the limited parameters, especially laboratory findings. The aim of our study was to assess predictors for IVIG resistance and CALs in patients with Kawasaki disease.

\section{Methods}

We retrospectively reviewed the medical records of patients diagnosed with KD at Children's Hospital, Zhejiang University School of Medicine, from May 2010 to May 2014. A total of $560 \mathrm{KD}$ patients, including 410 complete KD (cKD) and 150 incomplete KD (iKD) patients were enrolled in this study. The present study was reviewed and approved by the ethics committee of the same institution. Informed consent was obtained from each patient's parent or guardian. All patients received IVIG at a dosage of $1 \mathrm{~g} / \mathrm{kg} /$ day for 2 days and oral aspirin at $30-50 \mathrm{mg} / \mathrm{kg} /$ day. The dosage of aspirin was reduced to $3-5 \mathrm{mg} / \mathrm{kg} /$ day for 8 weeks at 3 day postnormal temperature. Laboratory findings were acquired at hospital admission and before IVIG administration, which included white blood cell count (WBC), proportion of neutrophils (N\%), hemoglobin (HB), C-reactive protein $(\mathrm{CRP})$, erythrocyte sedimentation rate (ESR), albumin (ALB), N-terminal pro-brain natriuretic peptide (NT-proBNP), interleukin-6 (IL-6) and IL-10.

\section{Definition of KD}

Complete KD was diagnosed when subjects had at least five of the following six principal clinical signs: 1) fever persisting for five or more days; 2) bilateral conjunctival congestion; 3 ) changes to the lips and oral cavity; 4) polymorphous exanthema; 5) changes to peripheral extremities; and 6) acute nonpurulent cervical lymphadenopathy [13]. Incomplete KD was defined as having four or fewer principal signs, with or without cardiac lesions [14].

\section{Definition of IVIG-resistant and CALs}

The IVIG-resistant was defined as those patients who remained febrile $48 \mathrm{~h}$ after administration of initial IVIG or recrudescent fever [15].

Echocardiography was used to assess CALs, which was performed before initial treatment and repeated at the point of 1 week, 2 weeks and 4 weeks after the initial treatment. Coronary artery was considered abnormal if the internal lumen diameter $>2.5 \mathrm{~mm}$ in children $<3$ years of age, $>3 \mathrm{~mm}$ in children 3-9 years of age, $>3.5 \mathrm{~mm}$ in children 9-14 years of age; the internal diameter of a segment measuring $\geq 1.5$ times that of an adjacent segment; and the lumen was clearly irregular [16].

\section{Statistical analysis}

Normally distributed data were presented as mean \pm SD and assessed by Student's $t$ test; continuous data of nonnormally distributed were expressed as median (interquartile range) and analyzed by the rank-sum test. Categorical data were presented as frequency (percentage) and compared by Chi-square test as appropriate. Receiver operating characteristic (ROC) curves were applied to determine the optimal cutoff values of laboratory findings, and multivariable logistic regression analysis was performed to evaluate the role of each parameter. All statistical analyses were undertaken using IBM SPSS Statistics 20.0 software. $p<0.05$ was considered to be statistically significant.

\section{Results}

\section{The basic demographic characteristics (Table 1)}

A total of $560 \mathrm{KD}$ patients were enrolled in this study, with 410 (73.2\%) cKD patients and 150 (26.8\%) iKD patients. The male to female ratio was 1.67:1 (350:210), with a ratio of cKD of 1.52:1 (247/163) and ratio of iKD of 2.19:1 (103/47). The patients with cKD had a median age of 25 months (interquartile range: 13-47.25 months); while the patients with iKD had a median age of 21.5 months (interquartile range: 10.75-40.25 months). No significant differences were observed in gender and age distribution between the cKD and iKD groups. Among these patients, 56 (10\%) were unresponsive to the initial IVIG treatment, with 30 (7.32\%) in the cKD group and $26(17.33 \%)$ in the iKD group. During the

Table 1 The basic demographic characteristics

\begin{tabular}{llll}
\hline & complete KD & incomplete KD & $p$ \\
\hline M/F & $247 / 163$ & $103 / 47$ & NS \\
Age(months) & $25(13-47.25)$ & $21.5(10.75-40.25)$ & NS \\
IVIG-resistant, $n$ (\%) & $30(7.32 \%)$ & $26(17.33 \%)$ & $p<0.01$ \\
CALs, $n$ (\%) & $95(23.17 \%)$ & $58(38.67 \%)$ & $p<0.01$ \\
\hline
\end{tabular}

$M / F$ males/females, NS no significant difference, ${ }^{*}$ Values are the median (interquartile range); IVIG intravenous immunoglobulin, CALs coronary artery lesions 
follow-up, CALs were detected in 153 (27.32\%) of the 560 patients with $95(23.17 \%)$ in the cKD group and 58 (38.67\%) in the iKD group. The incidences of IVIGresistant and CALs in the $\mathrm{iKD}$ group were significant higher than those in the cKD group (17.33\% vs. $7.32 \%$, $P<0.01$; $38.67 \%$ vs. $23.17 \%, P<0.01$; respectively). Additionally, the total incidence of CALs in the IVIGresistant patients $(27 / 56,48.2 \%)$ was significantly higher than that in the IVIG-responsive patients $(126 / 504$, $25 \%)$.

\section{Predictors for IVIG-resistance}

Table 2 showed that the levels of WBC, N\%, CRP, ESR, IL-6 and IL-10 were significantly higher in the IVIGresistant group compared to IVIG-responsive group both in cKD and iKD patients. The hemoglobin value was significantly lower in the IVIG-resistant group than in the IVIG-responsive group in iKD patients, but without significant difference in cKD patients. There were significant differences in the ALB levels between the IVIG-resistant and IVIG-responsive groups, and the ALB levels of IVIG-resistant patients were lower both in cKD and iKD patients. In cKD patients, the NT-proBNP level in the IVIG-resistant group was significantly higher than that in the IVIG-responsive group, but there was no significant difference in iKD patients.

The laboratory parameters which had statistical differences were performed with multivariable logistic regression analysis to evaluate the relative risk of each parameter; and receiver operating characteristic (ROC) curves were used to calculate sensitivity and specificity (Tables 3 \& 4). In cKD patients, a WBC cutoff value $>13.18 \times 10^{9} / \mathrm{L}$ had a sensitivity of $89.66 \%$ and a specificity of $46.32 \%$ for predicting IVIG-resistance; and a WBC cutoff value $>16 \times 10^{9} / \mathrm{L}$ yielded a sensitivity of $55.17 \%$ and a specificity of $69.47 \%$ for predicting IVIGresistance. In iKD patients, when WBC $>17.56 \times 10^{9} / \mathrm{L}$, the sensitivity and specificity for predicting IVIGresistance were 64 and $77.24 \%$, respectively. When WBC $>20 \times 10^{9} / \mathrm{L}$, the sensitivity and specificity for predicting IVIG-resistance were 37.93 and $88.68 \%$ in cKD patients, and 48 and $84.55 \%$ in iKD patients, respectively.

when $\mathrm{HB}<110 \mathrm{~g} / \mathrm{L}$, the sensitivity and specificity for predicting IVIG-resistance were 80 and $54.1 \%$, respectively in iKD patients.

When N\% $>70 \%$, the sensitivity and specificity for predicting IVIG-resistance were 60 and $60.42 \%$ in cKD patients, and 68 and $66.94 \%$ in iKD patients, respectively. When the N\% cutoff value $>80 \%$ was applied, the sensitivity and specificity for predicting IVIG-resistance were 46.67 and $83.91 \%$ in cKD patients, 44 and $91.74 \%$ in iKD patients, respectively.

In cKD patients, CRP level had a sensitivity of $82.76 \%$ and a specificity of $47.84 \%$ for predicting IVIGresistance at a cutoff point of $>70 \mathrm{mg} / \mathrm{L}$, and a sensitivity of $65.52 \%$ and a specificity of $62.7 \%$ for predicting IVIGresistance at a cutoff point of $>100 \mathrm{mg} / \mathrm{L}$. Accordingly, the sensitivity and specificity for iKD patients were 72 and $59.66 \%$ at a cutoff point of $>70 \mathrm{mg} / \mathrm{L}, 56$ and $74.79 \%$ when CRP $>100 \mathrm{mg} / \mathrm{L}$.

In cKD patients, ESR level had a sensitivity of $82.76 \%$ and a specificity of $33.71 \%$ for predicting IVIGresistance at a cutoff point of $>50 \mathrm{~mm} / \mathrm{h}$, and had a sensitivity of $31.03 \%$ and a specificity of $84.42 \%$ at a cutoff point of $>100 \mathrm{~mm} / \mathrm{h}$. In iKD patients, ESR levels had a sensitivity of $70.83 \%$ and a specificity of $65.81 \%$ for predicting IVIG-resistance at a cutoff point of $>80 \mathrm{~mm} / \mathrm{h}$, and had a sensitivity of $45.83 \%$ and a specificity of $90.6 \%$ at a cutoff point of $>100 \mathrm{~mm} / \mathrm{h}$.

When ALB $<32 \mathrm{~g} / \mathrm{L}$, the sensitivity and specificity for predicting IVIG-resistance were 72 and $83.19 \%$ in cKD patients, $42.86 \%$ and $92.73 \%$ in iKD patients, respectively.

In cKD patients, NT-proBNP levels had a sensitivity of $73.91 \%$ and a specificity of $76.43 \%$ for predicting IVIG-

Table 2 Comparisons of laboratory data between IVIG-resistant group and IVIG-responsive group both in cKD and iKD patients

\begin{tabular}{|c|c|c|c|c|c|c|c|c|c|c|}
\hline \multirow[b]{3}{*}{$\overline{\mathrm{WBC}}\left(\times 10^{9} / \mathrm{L}\right)$} & \multicolumn{4}{|c|}{ complete KD } & \multirow{3}{*}{$\begin{array}{l}p \\
0.001\end{array}$} & \multicolumn{4}{|c|}{ incomplete KD } & \multirow{3}{*}{$\begin{array}{l}p \\
0.000\end{array}$} \\
\hline & \multicolumn{2}{|c|}{ [n] IVIG-resistant } & \multicolumn{2}{|c|}{ [n] IVIG-responsive } & & \multicolumn{2}{|c|}{ [n] IVIG-resistant } & \multicolumn{2}{|c|}{ [n]IVIG-responsive } & \\
\hline & [29] & $18.69 \pm 6.74$ & {$[380]$} & $14.15 \pm 5.67$ & & {$[25]$} & $20.17 \pm 9.63$ & [148] & $14.35 \pm 5.94$ & \\
\hline$N \%$ & {$[30]$} & $73.88 \pm 14.36$ & {$[379]$} & $63.62 \pm 16.71$ & 0.001 & {$[25]$} & $73.19 \pm 16.43$ & [146] & $59.97 \pm 16.76$ & 0.000 \\
\hline $\mathrm{HB}(\mathrm{g} / \mathrm{L})$ & {$[30]$} & $104.43 \pm 12.48$ & {$[375]$} & $108.03 \pm 10.40$ & 0.134 & {$[25]$} & $100.56 \pm 12.00$ & {$[147]$} & $109.53 \pm 12.55$ & 0.002 \\
\hline $\mathrm{CRP}(\mathrm{mg} / \mathrm{L})$ & {$[29]$} & $115.58 \pm 48.87$ & {$[370]$} & $82.08 \pm 51.71$ & 0.001 & {$[25]$} & $97.00 \pm 50.49$ & [144] & $66.70 \pm 49.60$ & 0.010 \\
\hline $\operatorname{ESR}(\mathrm{mm} / \mathrm{h})$ & [29] & $81.55 \pm 31.15$ & {$[353]$} & $65.81 \pm 29.59$ & 0.013 & {$[24]$} & $91.13 \pm 35.27$ & [141] & $63.22 \pm 30.00$ & 0.001 \\
\hline $\mathrm{ALB}(\mathrm{g} / \mathrm{L})$ & {$[25]$} & $30.33 \pm 4.89$ & [339] & $35.91 \pm 4.29$ & 0.000 & {$[21]$} & $32.67 \pm 5.34$ & [131] & $37.39 \pm 4.31$ & 0.001 \\
\hline NT-proBNP (pg/ml) & {$[23]$} & 2192(607-4505) & {$[314]$} & $512.5(210.5-1195.5)$ & 0.000 & {$[14]$} & 775.(296.5-1780.75) & {$[104]$} & $300.5(107.25-925)$ & 0.094 \\
\hline IL-6 (pg/ml) & {$[21]$} & $68.10(38.7-221.35)$ & {$[302]$} & $29.55(10.45-93.25)$ & 0.003 & {$[17]$} & $130.70(20.90-491.05)$ & [103] & $11.90(5.07-50.58)$ & 0.001 \\
\hline IL-10 (pg/ml) & {$[21]$} & $14.40(5.25-60.05)$ & {$[302]$} & $6.50(4.00-12.23)$ & 0.006 & [17] & $12.10(4.8-45.6)$ & [103] & $4.75(3.18-8.75)$ & 0.001 \\
\hline
\end{tabular}

Data were expressed as mean \pm SD or median (interquartile range). $\mathrm{n}$ : number of patients, $W B C$ white blood cell count, $N \%$ proportion of neutrophils, $H B$ hemoglobin, CRP C-reactive protein, ESR erythrocyte sedimentation rate, ALB Albumin, NT-proBNP N-terminal pro-brain natriuretic peptide, IL-6: interleukin-6, IL-10 interleukin-10 
Table 3 Multivariable logistic regression analysis of laboratory data for predicting IVIG-resistant in cKD patients

\begin{tabular}{|c|c|c|c|c|c|c|}
\hline Cutoff & OR & $p$ & Sensitivity, \% & Specificity, \% & PPV, \% & NPV, \% \\
\hline & $(95 \% \mathrm{Cl})$ & & $(95 \% \mathrm{Cl})$ & $(95 \% \mathrm{Cl})$ & $(95 \% \mathrm{Cl})$ & $(95 \% \mathrm{Cl})$ \\
\hline \multicolumn{7}{|c|}{$\mathrm{WBC}\left(\times 10^{9} \mathrm{~L}\right)$} \\
\hline$>13.18$ & $7.803(2.327-26.161)$ & 0.001 & $89.66(69.44-94.50)$ & $46.32(41.36-51.34)$ & 11.3(7.83-16.05) & 98.32(95.19-99.43) \\
\hline$>16$ & $3.002(1.412-6.385)$ & 0.004 & $55.17(37.55-71.59)$ & $69.47(64.67-73.89)$ & $12.12(7.6-18.78)$ & $95.31(92.14-97.24)$ \\
\hline$>20$ & $4.524(2.017-10.145)$ & 0.000 & $37.93(22.69-56)$ & $88.68(85.1-91.49)$ & $20.37(11.77-32.9)$ & $94.9(92.13-96.77)$ \\
\hline \multicolumn{7}{|l|}{$N(\%)$} \\
\hline$>70$ & $2.341(1.096-5.001)$ & 0.028 & $60(42.32-75.41)$ & $60.42(55.42-65.22)$ & $10.71(6.89-16.3)$ & $95.02(91.5-97.13)$ \\
\hline$>80$ & $4.561(2.117-9.83)$ & 0.000 & $46.67(30.23-63.86)$ & $83.91(79.87-87.26)$ & 18.67(11.46-28.93) & $95.2(92.36-97.03)$ \\
\hline \multicolumn{7}{|c|}{$\mathrm{CRP}(\mathrm{mg} / \mathrm{L})$} \\
\hline$>70$ & $4.402(1.644-11.786)$ & 0.003 & $82.76(65.45-92.4)$ & $47.84(42.8-52.92)$ & $11.06(7.55-15.93)$ & $97.2(93.73-98.82)$ \\
\hline$>100$ & $3.231(1.46-7.15)$ & 0.004 & $65.52(47.35-80.06)$ & $62.7(57.67-67.48)$ & $12.1(7.89-18.13)$ & $95.8(92.56-97.74)$ \\
\hline \multicolumn{7}{|c|}{$\mathrm{ESR}(\mathrm{mm} / \mathrm{h})$} \\
\hline$>50$ & $2.441(0.908-6.559)$ & 0.077 & $82.76(65.45-92.4)$ & $33.71(28.98-38.79)$ & $9.3(6.33-13.47)$ & $95.9(90.91-98.27)$ \\
\hline$>100$ & $2.438(1.055-5.634)$ & 0.037 & $31.03(17.28-49.23)$ & $84.42(80.27-87.83)$ & $14.06(7.58-24.62)$ & 93.7(90.49-95.89) \\
\hline \multicolumn{7}{|l|}{ ALB $(g / L)$} \\
\hline$<32$ & $11.719(4.689-29.288)$ & 0.000 & $72(52.42-85.72)$ & $83.19(78.84-86.79)$ & $24(15.75-34.78)$ & $97.5(95.09-98.82)$ \\
\hline \multicolumn{7}{|c|}{ NT-proBNP(pg/ml) } \\
\hline$>1300$ & $9.189(3.496-24.156)$ & 0.000 & $73.91(53.53-87.45)$ & 76.43(71.44-80.79) & $18.68(12-27.9)$ & $97.5(94.78-98.88)$ \\
\hline \multicolumn{7}{|c|}{ IL-6 (pg/ml) } \\
\hline$>30$ & $6.243(1.801-21.637)$ & 0.004 & $85.71(65.36-95.02)$ & $50.99(45.38-56.58)$ & 10.84(6.97-16.49) & $98.0(94.53-99.35)$ \\
\hline$>45$ & $5.131(1.831-14.381)$ & 0.002 & $76.19(54.91-89.37)$ & 61.59(55.99-66.9) & $12.12(7.6-18.78)$ & 97.3(94.02-98.88) \\
\hline$>200$ & $2.309(0.798-6.683)$ & 0.123 & $23.81(10.63-45.09)$ & 88.08(83.94-91.26) & $12.2(5.32-25.54)$ & $94.3(90.98-96.48)$ \\
\hline \multicolumn{7}{|c|}{ IL-10 (pg/ml) } \\
\hline$>5$ & 2.614(0.858-7.96) & 0.091 & $80.95(60-92.33)$ & $38.08(32.79-43.67)$ & $8.33(5.27-12.94)$ & $96.6(91.68-98.69)$ \\
\hline$>30$ & $6.533(2.481-17.201)$ & 0.001 & $38.1(20.75-59.12)$ & $91.39(87.68-94.06)$ & $23.53(12.44-40)$ & $95.5(92.46-97.35)$ \\
\hline
\end{tabular}

$O R$ odds ratio, $C l$ confidence interval, $P P V$ positive predictive value, NPV: negative predictive value, WBC white blood cell count, N\% proportion of neutrophils, $C R P$ C-reactive protein, ESR erythrocyte sedimentation rate, ALB Albumin, NT-proBNP N-terminal pro-brain natriuretic peptide, IL-6 interleukin-6, IL-10 interleukin-10

resistantace a cutoff point of $>1300 \mathrm{pg} / \mathrm{ml}$. In iKD patients, NT-proBNP level had a sensitivity of $78.57 \%$ and a specificity of $56.67 \%$ for predicting IVIG-resistantat a cutoff point of $>360 \mathrm{pg} / \mathrm{ml}$, and had a sensitivity of $28.57 \%$ and a specificity of $83.33 \%$ at a cutoff point of $>1300 \mathrm{pg} / \mathrm{ml}$.

In cKD patients, IL-6 level had a sensitivity of $85.71 \%$ and a specificity of $50.99 \%$ for predicting IVIGresistance at a cutoff value of $>30 \mathrm{pg} / \mathrm{ml}$, a sensitivity of $76.19 \%$ and a specificity of $61.59 \%$ at a cutoff value of $>45 \mathrm{pg} / \mathrm{ml}$, and a sensitivity of $23.81 \%$ and a specificity of $88.08 \%$ at a cutoff value of $>200 \mathrm{pg} / \mathrm{ml}$. In iKD patients, IL-6 level had a sensitivity of $88.24 \%$ and a specificity of $55.81 \%$ for predicting IVIG-resistance at a cutoff value of $>15 \mathrm{pg} / \mathrm{ml}$, and a sensitivity of $70.59 \%$ and a specificity of $66.28 \%$ at a cutoff value of $>25 \mathrm{pg} / \mathrm{ml}$, and a sensitivity of $52.94 \%$ and a specificity of $93.02 \%$ at a cutoff value of $>120 \mathrm{pg} / \mathrm{ml}$. In cKD patients, IL-10 level had a sensitivity of $80.95 \%$ and a specificity of $38.08 \%$ for predicting IVIG-resistance at a cutoff value of $>5 \mathrm{pg} / \mathrm{ml}$, and had a sensitivity of $38.1 \%$ and a specificity of $91.39 \%$ at a cutoff value of $>30 \mathrm{pg} / \mathrm{ml}$. In iKD patients, IL-10 level had a sensitivity of $64.71 \%$ and a specificity of $74.42 \%$ for predicting IVIG-resistance at a cutoff value of $>8 \mathrm{pg} / \mathrm{ml}$, and had a sensitivity of $29.41 \%$ and a specificity of $95.35 \%$ at a cutoff value of $>30 \mathrm{pg} / \mathrm{ml}$.

\section{Predictor for CALs}

Table 5 shows that the levels of WBC, ESR were significantly higher in patients with CALs than those in patients without CALs both in the cKD and iKD groups; whereas there were no statistical differences in the levels of N\%, NT-proBNP, IL-6 and IL-10 between patients with CALs and those without CALs. The levels of HB and ALB were significantly lower in CKD patients with CALs than those without. CRP value was significantly higher in CKD patients with CALs than those without. In iKD patients, no significant differences were observed in the levels of HB, ALB and CRP between patients with CALs and those without. 
Table 4 Multivariable logistic regression analysis of laboratory data for predicting IVIG-resistant in iKD patients

\begin{tabular}{|c|c|c|c|c|c|c|}
\hline Cutoff & OR & $p$ & Sensitivity, \% & Specificity, \% & PPV, \% & NPV, \% \\
\hline & $(95 \% \mathrm{Cl})$ & & $(95 \% \mathrm{Cl})$ & $(95 \% \mathrm{Cl})$ & $(95 \% \mathrm{Cl})$ & $(95 \% \mathrm{Cl})$ \\
\hline \multicolumn{7}{|c|}{ WBC $\left(\times 10^{9} / \mathrm{L}\right)$} \\
\hline$>17.56$ & $6.032(2.406-15.12)$ & 0.000 & $64(44.52-79.75)$ & $77.24(69.07-83.75)$ & $36.3(23.78-51.13)$ & 91.35(84.37-95.38) \\
\hline$>20$ & $5.053(2.004-12.736)$ & 0.000 & $48(30.03-66.5)$ & $84.55(77.13-89.88)$ & $38.7(23.73-56.18)$ & 88.8(81.91-93.39) \\
\hline \multicolumn{7}{|l|}{$N(\%)$} \\
\hline$>70$ & $4.303(1.712-10.817)$ & 0.002 & $68(48.41-82.79)$ & 66.94(58.15-74.69) & 29.8(19.53-42.66) & $91.0(83.25-95.37)$ \\
\hline$>80$ & $8.721(3.142-24.21)$ & 0.000 & $44(26.67-62.93)$ & $91.74(85.45-95.45)$ & $52.3(32.37-71.66)$ & 88.8(82.08-93.21) \\
\hline \multicolumn{7}{|l|}{$\mathrm{HB}(\mathrm{g} / \mathrm{L})$} \\
\hline$<110$ & $5.25(1.702-16.197)$ & 0.004 & $80(60.87-91.14)$ & $54.1(45.27-62.68)$ & 26.3(17.73-37.18) & 92.9(84.55-96.95) \\
\hline \multicolumn{7}{|c|}{ CRP (mg/L) } \\
\hline$>70$ & $3.804(1.476-9.803)$ & 0.006 & $72(52.42-85.72)$ & 59.66(50.68-68.04) & $27.27(18-39.04)$ & $91.0(82.62-95.58)$ \\
\hline$>100$ & $3.776(1.548-9.209)$ & 0.003 & $56(37.07-73.33)$ & 74.79(66.3-81.73) & $31.82(20-46.56)$ & 89(81.37-93.75) \\
\hline \multicolumn{7}{|c|}{$\operatorname{ESR}(\mathrm{mm} / \mathrm{h})$} \\
\hline$>80$ & $4.675(1.791-12.204)$ & 0.002 & $70.83(50.83-85.09)$ & 65.81(56.84-73.78) & 29.8(19.53-42.66) & 91.67(83.78-95.9) \\
\hline$>100$ & $8.154(2.955-22.499)$ & 0.000 & 45.83(27.89-64.93) & $90.6(83.95-94.67)$ & $50(30.72-69.28)$ & $89.08(82.2-93.5)$ \\
\hline \multicolumn{7}{|l|}{ ALB (g/L) } \\
\hline$<32$ & $7.5(2.543-22.117)$ & 0.000 & $42.86(24.47-63.45)$ & $92.73(86.3-96.27)$ & $52.9(30.96-73.83)$ & $89.47(82.5-93.88)$ \\
\hline \multicolumn{7}{|c|}{ NT-proBNP (pg/ml) } \\
\hline$>360$ & $4.795(1.252-18.366)$ & 0.022 & $78.57(52.41-92.43)$ & $56.67(46.36-66.42)$ & $22(12.75-35.24)$ & 94.4(84.89-98.09) \\
\hline$>1300$ & $2.000(0.553-7.231)$ & 0.29 & $28.57(11.72-54.65)$ & $83.33(74.31-89.63)$ & 21.05(8.51-43.33) & 88.2(79.68-93.48) \\
\hline \multicolumn{7}{|c|}{ IL-6 (pg/ml) } \\
\hline$>15$ & $9.474(2.04-43.995)$ & 0.004 & $88.24(65.66-96.71)$ & $55.81(45.29-65.84)$ & 28.3(17.97-41.57) & $96(86.54-98.9)$ \\
\hline$>25$ & $4.717(1.516-14.676)$ & 0.007 & $70.59(46.87-86.72)$ & $66.28(55.78-75.38)$ & $29.2(17.61-44.48)$ & $91.9(82.47-96.51)$ \\
\hline$>120$ & $15(4.242-53.042)$ & 0.000 & $52.94(30.96-73.83)$ & $93.02(85.6-96.76)$ & $60(35.75-80.18)$ & $90.9(83.07-95.32)$ \\
\hline \multicolumn{7}{|c|}{$\mathrm{IL}-10(\mathrm{pg} / \mathrm{ml})$} \\
\hline$>8$ & $5.333(1.764-16.125)$ & 0.003 & $64.71(41.3-82.69)$ & $74.42(64.29-82.46)$ & $33.3(19.75-50.39)$ & $91.4(82.53-96.01)$ \\
\hline$>30$ & $8.542(2.008-36.328)$ & 0.001 & $29.41(13.28-53.13)$ & 95.35(88.64-98.18) & $55.5(26.67-81.12)$ & 87.23(79-92.54) \\
\hline
\end{tabular}

OR odds ratio, $C l$ confidence interval, $P P V$ positive predictive value, NPV negative predictive value, WBC white blood cell count, N\% proportion of neutrophils, HB: hemoglobin, CRP C-reactive protein, ESR erythrocyte sedimentation rate, ALB Albumin, NT-proBNP N-terminal pro-brain natriuretic peptide, IL-6 interleukin-6, IL-10 interleukin-10

Table 5 Comparisons of laboratory data between CALs + group and CALs- group both in CKD and iKD patients

\begin{tabular}{|c|c|c|c|c|c|c|c|c|c|c|}
\hline \multirow[b]{3}{*}{$\overline{W B C}\left(\times 10^{9} / L\right)$} & \multicolumn{4}{|c|}{ complete KD } & \multirow{3}{*}{$\begin{array}{l}p \\
0.000\end{array}$} & \multicolumn{4}{|c|}{ incomplete KD } & \multirow{3}{*}{$\begin{array}{l}p \\
0.007\end{array}$} \\
\hline & \multicolumn{2}{|c|}{ [n] CALs+ } & \multicolumn{2}{|c|}{ [n] CALs- } & & \multicolumn{2}{|c|}{ [n] CALs+ } & \multicolumn{2}{|c|}{ [n] CALs- } & \\
\hline & [95] & $16.61 \pm 7.05$ & [314] & $13.84 \pm 5.31$ & & {$[56]$} & $17.31 \pm 8.48$ & [92] & $14.14 \pm 5.67$ & \\
\hline$N \%$ & [95] & $66.84 \pm 15.41$ & {$[314]$} & $63.63 \pm 17.08$ & 0.084 & {$[55]$} & $64.28 \pm 17.42$ & {$[91]$} & $61.00 \pm 17.35$ & 0.272 \\
\hline $\mathrm{HB}(\mathrm{g} / \mathrm{L})$ & [94] & $105.16 \pm 11.96$ & {$[311]$} & $108.55 \pm 10.03$ & 0.014 & {$[55]$} & $106.87 \pm 12.90$ & {$[92]$} & $108.68 \pm 12.87$ & 0.411 \\
\hline $\mathrm{CRP}(\mathrm{mg} / \mathrm{L})$ & [89] & $100.00 \pm 53.47$ & {$[310]$} & $80.07 \pm 51.03$ & 0.002 & {$[53]$} & $80.44 \pm 51.63$ & {$[91]$} & $67.02 \pm 50.09$ & 0.131 \\
\hline $\operatorname{ESR}(\mathrm{mm} / \mathrm{h})$ & [92] & $73.78 \pm 32.29$ & {$[290]$} & $64.85 \pm 28.92$ & 0.019 & {$[55]$} & $77.78 \pm 33.60$ & {$[86]$} & $61.70 \pm 30.46$ & 0.005 \\
\hline ALB (g/L) & {$[86]$} & $33.48 \pm 5.02$ & {$[278]$} & $36.16 \pm 4.21$ & 0.000 & {$[50]$} & $35.81 \pm 5.09$ & {$[81]$} & $37.14 \pm 4.56$ & 0.134 \\
\hline NT-proBNP (pg/ml) & {$[76]$} & $669.5(278.25-1583)$ & {$[261]$} & $497(203-1374)$ & 0.069 & {$[39]$} & $334(135-796)$ & {$[65]$} & 303(90-1101.5) & 0.869 \\
\hline IL-6 (pg/ml) & {$[71]$} & $31.80(13.90-120.20)$ & {$[252]$} & $30.45(10.86-94.66)$ & 0.590 & [37] & $19.80(4.9-63.45)$ & {$[66]$} & $13.35(6.70-56.33)$ & 0.956 \\
\hline IL-10 (pg/ml) & [71] & $6.30(3.7-13.4)$ & {$[252]$} & $6.70(4.20-13.13)$ & 0.748 & {$[37]$} & $5.80(3.35-10.80)$ & {$[66]$} & $5.00(3.35-12.18)$ & 0.921 \\
\hline
\end{tabular}


Multivariable logistic regression analysis and receiver operating characteristic (ROC) curves were used to evaluate the relative risk, sensitivity and specificity of each parameter (Tables 6 and 7). In cKD patients, WBC level had a sensitivity of $62.11 \%$ and a specificity of $58.92 \%$ for predicting CALs at a cutoff value $>14.25 \times$ $10^{9} / \mathrm{L}$, and a sensitivity of $22.11 \%$ and a specificity of $89.49 \%$ at a cutoff value $>20 \times 10^{9} / \mathrm{L}$. In iKD patients, WBC level had a sensitivity of $60.71 \%$ and a specificity of $50 \%$ for predicting CALs at a cutoff value $>14.25 \times 10^{9} / \mathrm{L}$, and a specificity of $35.71 \%$ and a specificity of $88.04 \%$ at a cutoff value $>20 \times 10^{9} / \mathrm{L}$. In cKD patients, when $\mathrm{HB}<110 \mathrm{~g} / \mathrm{L}$, the sensitivity and specificity for predicting CALs were 68.09 and $44.37 \%$, when $\mathrm{HB}<100 \mathrm{~g} / \mathrm{L}$, the sensitivity and specificity were $30 . \%$ and $82.96 \%$, respectively. In cKD patients, CRP levels had a sensitivity of $94.38 \%$ and a specificity of $16.45 \%$ for predicting CALs at a cutoff point of $>25 \mathrm{mg} / \mathrm{L}$, and had a sensitivity of $29.21 \%$ and a specificity of $82.26 \%$ at a cutoff point of $>140 \mathrm{mg} / \mathrm{L}$. In cKD patients, ESR levels had a sensitivity of $53.26 \%$ and a specificity of $64.14 \%$ for predicting CALs at a cutoff point of $>75 \mathrm{~mm} / \mathrm{h}$. In iKD patients, ESR levels had a sensitivity of $61.82 \%$ and a specificity of $65.12 \%$ for predicting CALs at a cutoff point of $>75 \mathrm{~mm} / \mathrm{h}$. When $\mathrm{ALB}<30 \mathrm{~g} / \mathrm{L}$, the sensitivity and specificity for predicting CALs in cKD patients were 23.26 and $90.65 \%$, respectively.

\section{Discussion}

Treatment with IVIG and aspirin significantly reduces the rate of coronary artery lesions. However, about $10 \%$ to $20 \%$ of children will have persistent or recrudescent fever after the initial IVIG therapy $[4,8,17]$, and patients not responsive to IVIG therapy are at high risk of developing coronary artery lesions [7]. Therefore, Identification of the risk factors of IVIG-resistant and CALs is crucial. Kobayashi et al. [9] used demographic and laboratory characteristics, including age in months, day of illness at initial treatment, percentage of neutrophils, platelet count, and serum aspartate aminotransferase (AST), sodium, and CRP to generate a scoring model, which had a sensitivity of $86 \%$ and a specificity of $68 \%$ for predicting IVIGresistance. Fukunishi et al. [18] had reported that serum levels of C-reactive protein, total bilirubin, lactate dehydrogenase, $\gamma$-glutamyltranspeptidase were significantly higher, and the hemoglobin value was significantly lower in the IVIG non-responsive group. In our research, the results of multivariable logistic regression analysis suggested that elevated WBC, N\%, CRP, ESR, IL-6, IL-10 and low ALB level were independent risk factors for IVIGresistance both in $\mathrm{CKD}$ and $\mathrm{iKD}$ patients. In the patients with $\mathrm{iKD}, \mathrm{HB}<110 \mathrm{~g} / \mathrm{L}$ can be diagnosed IVIG-resistant with $\mathrm{OR}=5.25$, while the difference of hemoglobin value between the IVIG-resistance and IVIG-responsive groups in $\mathrm{CKD}$ patients failed to reach statistical significance. Durongpisitkul et al. [17] found that low hemoglobin $(<10 \mathrm{~g} / \mathrm{dl})$, high neutrophil count $(>75 \%)$, high band count, and a low albumin were associated with unresponsive to the initial IVIG treatment. High levels of WBC, N\%, CRP, ESR and anemia probably reflected the severity of ongoing inflammation in patients with KD.

In the present study, the levels of ALB in the IVIGresistant group were significantly lower than the IVIGresponsive group both in $\mathrm{CKD}$ and $\mathrm{iKD}$ patients; there were very high sensitivity and specificity for predicting IVIG-resistant (72 and 83.19\%) in cKD patients when

Table 6 Multivariable logistic regression analysis of laboratory data for predicting CALs in cKD patients

\begin{tabular}{|c|c|c|c|c|c|c|}
\hline Cutoff & $\begin{array}{l}\text { OR } \\
(95 \% \mathrm{Cl})\end{array}$ & $p$ & $\begin{array}{l}\text { Sensitivity, \% } \\
(95 \% \mathrm{Cl})\end{array}$ & $\begin{array}{l}\text { Specificity, \% } \\
(95 \% \text { Cl) }\end{array}$ & $\begin{array}{l}\text { PPV, \% } \\
(95 \% \mathrm{Cl})\end{array}$ & $\begin{array}{l}\text { NPV, \% } \\
(95 \% \mathrm{Cl})\end{array}$ \\
\hline \multicolumn{7}{|c|}{$\overline{W B C}\left(\times 10^{9} / \mathrm{L}\right)$} \\
\hline$>14.25$ & $2.35(1.467-3.766)$ & 0.000 & $62.11(52.06-71.21)$ & 58.92(53.4-64.22) & 31.3(25.18-38.33) & 83.71(78.27-88) \\
\hline$>20$ & $2.416(1.321-4.421)$ & 0.004 & $22.11(14.94-31.44)$ & $89.49(85.61-92.42)$ & $38.8(27.04-52.21)$ & $79.1(74.63-83.06)$ \\
\hline \multicolumn{7}{|l|}{$\mathrm{HB}(\mathrm{g} / \mathrm{L})$} \\
\hline$<110$ & $1.671(1.017-2.744)$ & 0.043 & 68.09(58.11-76.64) & $44.37(38.95-49.93)$ & $27(21.75-32.99)$ & $82.14(75.65-87.2)$ \\
\hline$<100$ & $2.217(1.334-3.684)$ & 0.002 & $30.85(22.42-40.79)$ & 82.96(78.38-86.73) & $35.3(25.89-46.16)$ & 79.8(75.16-83.89) \\
\hline \multicolumn{7}{|c|}{ CRP (mg/L) } \\
\hline$>25$ & $3.308(1.278-8.561)$ & 0.014 & $94.38(87.51-97.58)$ & $16.45(12.74-20.98)$ & 24.4(20.24-29.31) & $91.0(80.74-96.13)$ \\
\hline$>140$ & 1.913(1.113-3.29) & 0.019 & $29.21(20.78-39.36)$ & $82.26(77.62-86.11)$ & $32.1(22.94-42.88)$ & $80.19(75.46-84.2)$ \\
\hline \multicolumn{7}{|c|}{$\mathrm{ESR}(\mathrm{mm} / \mathrm{h})$} \\
\hline$>75$ & $2.038(1.268-3.276)$ & 0.003 & $53.26(43.14-63.12)$ & 64.14(58.47-69.44) & $32.0(25.15-39.78)$ & $81.2(75.67-85.75)$ \\
\hline \multicolumn{7}{|l|}{ ALB (g/L) } \\
\hline$<30$ & $3.003(1.596-5.651)$ & 0.001 & 23.26(15.59-33.21) & $90.65(86.65-93.54)$ & $43.4(30.21-57.75)$ & $79.2(74.45-83.34)$ \\
\hline
\end{tabular}


Table 7 Multivariable logistic regression analysis of laboratory data for predicting CALs in iKD patients

\begin{tabular}{|c|c|c|c|c|c|c|}
\hline Cutoff & OR & $p$ & Sensitivity, \% & Specificity, \% & PPV, \% & NPV, \% \\
\hline & $(95 \% \mathrm{Cl})$ & & $(95 \% \mathrm{Cl})$ & $(95 \% \mathrm{Cl})$ & $(95 \% \mathrm{Cl})$ & $(95 \% \mathrm{Cl})$ \\
\hline \multicolumn{7}{|c|}{ WBC $\left(\times 10^{9} / \mathrm{L}\right)$} \\
\hline$>14.25$ & $1.545(0.787-3.033)$ & 0.206 & $60.71(47.63-72.42)$ & $50(39.99-60.01)$ & $42.5(32.26-53.43)$ & 67.65(55.84-77.56) \\
\hline$>20$ & $4.091(1.777-9.419)$ & 0.001 & $35.71(24.46-48.81)$ & 88.04(79.85-93.19) & 64.5(46.95-78.88) & $69.2(60.37-76.87)$ \\
\hline \multicolumn{7}{|l|}{$\mathrm{HB}(\mathrm{g} / \mathrm{L})$} \\
\hline$<110$ & $1.676(0.845-3.323)$ & 0.14 & $63.64(50.42-75.07)$ & $32.61(23.89-42.72)$ & $36.08(27.22-46)$ & $60(46.18-72.39)$ \\
\hline$<100$ & $1.231(0.582-2.603)$ & 0.587 & $27.27(17.28-40.23)$ & $76.09(66.44-83.64)$ & $40.5(26.35-56.51)$ & 63.6(54.33-72.02) \\
\hline \multicolumn{7}{|c|}{ CRP (mg/L) } \\
\hline$>25$ & $2.373(0.988-5.7)$ & 0.053 & $84.91(72.95-92.15)$ & $29.67(21.26-39.72)$ & $41.2(32.49-50.67)$ & $77.1(60.98-87.93)$ \\
\hline$>140$ & $2.386(0.917-6.209)$ & 0.075 & $20.75(12-33.46)$ & $90.11(82.26-94.71)$ & $55(34.21-74.18)$ & $66.1(57.43-73.86)$ \\
\hline \multicolumn{7}{|c|}{$\operatorname{ESR}(\mathrm{mm} / \mathrm{h})$} \\
\hline$>75$ & $3.022(1.498-6.097)$ & 0.002 & $61.82(48.61-73.48)$ & $65.12(54.59-74.35)$ & $53.1(41.07-64.82)$ & $72.7(61.88-81.42)$ \\
\hline \multicolumn{7}{|l|}{$\operatorname{ALB}(g / L)$} \\
\hline$<30$ & $2.474(0.74-8.273)$ & 0.141 & $14(6.95-26.19)$ & $93.83(86.35-97.33)$ & $58.3(31.95-80.67)$ & 63.8(54.93-71.94) \\
\hline
\end{tabular}

$O R$ odds ratio, $C l$ confidence interval, $P P V$ positive predictive value, $N P V$ negative predictive value, $W B C$ white blood cell count, $H B$ hemoglobin, $C R P C-$ reactive protein, ESR erythrocyte sedimentation rate, ALB Albumin

ALB $<32 \mathrm{~g} / \mathrm{L}$. As Terai et al. [19] revealed that the IVIGresistant group had significantly severe hypoalbuminemia compared to the IVIG-responsive group. The vascular leakage was supposed as a key feature of KD pathophysiology, which led to hypoalbuminemia.

NT-proBNP is secreted and released by ventricular cardiomyocytes in response to myocardial wall stress and ischemia, which was widely used as an important biomarker of cardiovascular diseases [20]. A recent meta-analysis reported by Lin et al. [21] showed that NT-proBNP had high diagnostic value for identifying $\mathrm{KD}$ in patients with protracted undifferentiated febrile illness. Ye et al. [22] reported thatthe NT-proBNP levels in IVIG-non-responsive $\mathrm{KD}$ patients were significantly higher than IVIG-responsive KD patients (1023.5 vs. 2367.5). In our research, the NT-proBNP values in the IVIG-resistant group was significantly higher than in the IVIG-responsive group in cKD patients, but failed to reach significant difference in iKD patients. In cKD patients, when NT-proBNP $>1300 \mathrm{pg} / \mathrm{ml}$, the diagnosis sensitivity and specificity for predicting IVIG-resistance were 73.91 and $76.43 \%$, respectively. Elevated NTproBNP values may be associated with the vasculitis and myocarditis caused by KD.

Th1 and Th2 cytokines were considered helpful for predicting the disease prognosis and targeting treatment strategies in patients with $\mathrm{KD}$ as Wang et al. [15] reported previously. In our study, we found that the IL-6 and IL-10 values of the IVIG-resistant group were significantly higher than the IVIG-responsive group both in cKD and iKD patients, which was consistent with the study of Wang et al.
Previously, several studies have focused on risk factors for coronary artery lesions, particularly coronary artery aneurysms. Beiser et al. [10] developed instruments that incorporate baseline neutrophils and band counts, hemoglobin concentration, platelet count, and temperature on the day after infusion, to predict coronary artery abnormalities. However, the accuracy of the instrument was not consistently high in several validation studies, and the instrument may be inaccurate in patients who present after the tenth day of illness or who were diagnosed with iKD. In China, a recent study suggested that male gender, younger age, intravenous immunoglobulin dose, delayed administration, high platelet level and elevated ESR are predictive for CALs [6], but they defined CALs with the criteria of Japan Ministry of Health, which may be not suitable for Chinese population. In our study, the levels of WBC and ESR were significantly higher in patients with CALs compared to patients without CALs both in the cKD and iKD groups. In the cKD group, patients with high CRP, low levels of HB and ALB had a high risk for CALs.

The total incidence of CALs in IVIG-resistant patients was significantly higher than in patients responsive to IVIG in our research, which suggested that the formation of CALs was associated with IVIG-resistance. Interestingly, nearly half of the parameters in our study considered as effective predictors for IVIG-resistant but failed to reach statistical differences between patients with CALs and without CALs. It may be explained with the following points:1) The IVIG unresponsiveness may reflect only severity of ongoing inflammation, whereas 
development of CALs might be affected by both ongoing inflammation and hemodynamics [9]. 2) There are missing laboratory data in a proportion of patients. 3) In our study, criteria of CALs were different from other countries; in addition, patients had been diagnosed with CALs when echocardiogram was positive (including transient dilation) at any time during the follow-up, which might lead to misclassification and overestimate the prevalence of CALs. Therefore, prospective clinical large cohort trials are warranty.

\section{Conclusions}

The levels of laboratory findings including WBC count, N\%, HB, CRP, ESR, ALB, NT-proBNP, IL-6 and IL-10 can be used as predictors of IVIG-resistant andCALs. Especially, in cKD patients, when albumin $<32 \mathrm{~g} / \mathrm{L}$, the sensitivity and specificity for predicting IVIG-resistance were72 and $83.19 \%$, respectively. NT-proBNP level had a high sensitivity of $73.91 \%$ and a specificity of $76.43 \%$ for predicting IVIG-resistant at a cutoff pointof $>1300 \mathrm{pg} /$ ml. In iKD patients, ESR levels had a sensitivity of $70.83 \%$ and a specificity of $65.81 \%$ for predicting IVIGresistance at a cutoff pointof $>80 \mathrm{~mm} / \mathrm{h}$. Interleukin-6 levels had a sensitivity of $70.59 \%$ and a specificity of $66.28 \%$ at a cutoff value of $>25 \mathrm{pg} / \mathrm{ml}$. Interleukin- 10 levels had a sensitivity of $64.71 \%$ and a specificity of $74.42 \%$ for predicting IVIG-resistance at a cutoff value of $>8 \mathrm{pg} / \mathrm{ml}$. ESR levels had a sensitivity of $61.82 \%$ and a specificity of $65.12 \%$ for predicting CALs at a cutoff point of $>75 \mathrm{~mm} / \mathrm{h}$. Albumin and NT-proBNP were considered as the most effective predictors for IVIG resistance in the present study. Our study may be helpful for the treatment and long-term management of KD patients. Additional therapy and careful follow-up such as more frequent echocardiography should be considered in the patients with high risks for IVIG-resistant and CALs.

\section{Abbreviations \\ ALB: Albumin; CALs: Coronary artery lesions; CALs-: Patients without coronary artery lesions.; CALs+: Patients with coronary artery lesions; CKD: Complete kawasaki disease; CRP: C-reactive protein; ESR: Erythrocyte sedimentation rate; HB: Hemoglobin; iKD: Incomplete kawasaki disease; IL-10: Interleukin-10; IL-6: Interleukin-6; IVIG: Intravenous immunoglobulin; KD: Kawasaki disease; N\%: Proportion of neutrophils; NT-proBNP: N-terminal pro-brain natriuretic peptide; WBC: White blood cell count}

\section{Acknowledgements}

Not applicable.

\section{Funding}

This work is supported, in part, by grants from The National Natural Science Foundation of China $(81270177,81670251)$ and Special Major Science and Technology Project of Zhejiang Province (2013C03043-1).The role of the funding body was in the design of the study and collection, analysis, and interpretation of data and in writing the manuscript.

Availability of data and material Not applicable..

\section{Authors' contributions}

$\mathrm{XT}$ and GF were mainly responsible for the study conception and design, and writing the manuscript. XT, WY, FS, WW, XC, ZY and GF acquired, analyzed and interpreted the patient data.

All authors read and approved the final manuscript.

\section{Competing interests}

The authors declare that they have no competing interests.

\section{Consent for publication}

Not applicable.

Ethics approval and consent to participate

The study was reviewed and approved by the ethics committee of the Children's Hospital, Zhejiang University School of Medicine. Informed consent was obtained from each patient's parent or guardian.

\section{Publisher's Note}

Springer Nature remains neutral with regard to jurisdictional claims in published maps and institutional affiliations.

Received: 8 January 2017 Accepted: 15 March 2017

Published online: 21 March 2017

\section{References}

1. Newburger JW, Takahashi M, Gerber MA, Gewitz MH, Tani LY, Burns JC, et al. Diagnosis, treatment, and long-term management of Kawasaki disease: a statement for health professionals from the Committee on Rheumatic Fever, Endocarditis and Kawasaki Disease, Council on Cardiovascular Disease in the Young. Am Heart Assoc Circ. 2004;110:17.

2. Kawasaki T. Acute febrile mucocutaneous syndrome with lymphoid involvement with specific desquamation of the fingers and toes in children. Arerugi. 1967;16:3.

3. Mori M, Imagawa T, Yasui K, Kanaya A, Yokota S. Predictors of coronary artery lesions after intravenous gamma-globulin treatment in Kawasaki disease. J Pediatr. 2000;137:2

4. Ashouri N, Takahashi M, Dorey F, Mason W. Risk factors for nonresponse to therapy in Kawasaki disease. J Pediatr. 2008;153:3.

5. Tremoulet AH, Best BM, Song S, Wang S, Corinaldesi E, Eichenfield JR, et al. Resistance to intravenous immunoglobulin in children with Kawasaki disease. J Pediatr. 2008;153:1.

6. Ruan Y, Ye B, Zhao XD. Clinical characteristics of Kawasaki syndrome and the risk factors for coronary artery lesions in China. Pediatr Infect Dis J. 2013;32:10.

7. JCS Joint Working Group. Guidelines for Diagnosis and Management of Cardiovascular Sequelae in Kawasaki Disease (JCS 2013). Circ J. 2014:78:10.

8. Egami K, Muta H, Ishii M, Suda K, Sugahara Y, lemura M, et al. Prediction of resistance to intravenous immunoglobulin treatment in patients with Kawasaki disease. J Pediatr. 2006;149:2.

9. Kobayashi T. Prediction of Intravenous Immunoglobulin Unresponsiveness in Patients With Kawasaki Disease. Circulation. 2006;113:22.

10. Beiser AS, Takahashi M, Baker AL, Sundel RP, Newburger JW. A predictive instrument for coronary artery aneurysms in Kawasaki disease. US Multicenter Kawasaki Disease Study Group. Am J Cardiol. 1998;81:9.

11. Honkanen VE, McCrindle BW, Laxer RM, Feldman BM, Schneider R, Silverman ED. Clinical relevance of the risk factors for coronary artery inflammation in Kawasaki disease. Pediatr Cardiol. 2003;24:2.

12. Sabharwal T, Manlhiot C, Benseler SM, Tyrrell PN, Chahal N, Yeung RS, et al. Comparison of factors associated with coronary artery dilation only versus coronary artery aneurysms in patients with Kawasaki disease. Am J Cardiol. 2009;104:12.

13. Ayusawa M, Sonobe T, Uemura S, Ogawa S, Nakamura Y, Kiyosawa N, et al. Revision of diagnostic guidelines for Kawasaki disease (the 5 th revised edition). Pediatr Int. 2005;47:2.

14. Sudo D, Monobe Y, Yashiro M, Mieno MN, Uehara R, Tsuchiya K, et al. Coronary artery lesions of incomplete Kawasaki disease: a nationwide survey in Japan. Eur J Pediatr. 2012;171:4.

15. Wang YJ, Wang W, Gong FQ, Fu S, Zhang Q, Hu J, et al. Evaluation of intravenous immunoglobulin resistance and coronary artery lesions in relation to Th1/Th2 cytokine profiles in patients with Kawasaki disease. Arthritis Rheum. 2013;65:3. 
16. Fu SL, Gong FQ, Xie CH, Zhu W, Wang W, Shen H, et al. S100A12 on circulating endothelial cells surface in children with Kawasaki disease. Pediatr Res. 2010;68:2.

17. Durongpisitkul K, Soongswang J, Laohaprasitiporn D, Nana A, Prachuabmoh C, Kangkagate C. Immunoglobulin failure and retreatment in Kawasaki disease. Pediatr Cardiol. 2003;24:2

18. Fukunishi M, Kikkawa M, Hamana K, Onodera T, Matsuzaki K, Matsumoto Y, et al. Prediction of non-responsiveness to intravenous high-dose gamma-globulin therapy in patients with Kawasaki disease at onset. J Pediatr. 2000;137:2.

19. Terai M, Honda T, Yasukawa K, Higashi K, Hamada H, Kohno Y. Prognostic impact of vascular leakage in acute Kawasaki disease. Circulation. 2003:108:3.

20. de Lemos JA, McGuire DK, Drazner MH. B-type natriuretic peptide in cardiovascular disease. Lancet. 2003;362:9380.

21. Lin KH, Chang SS, Yu CW, Lin SC, Liu SC, Chao HY, et al. Usefulness of natriuretic peptide for the diagnosis of Kawasaki disease: a systematic review and meta-analysis. BMJ Open. 2015;5:4.

22. Ye Q, Shao WX, Shang SQ, Zhang T, Hu J, Zhang CC. A Comprehensive Assessment of the Value of Laboratory Indices in Diagnosing Kawasaki Disease. Arthritis Rheumatol. 2015;67:7.

\section{Submit your next manuscript to BioMed Central} and we will help you at every step:

- We accept pre-submission inquiries

- Our selector tool helps you to find the most relevant journal

- We provide round the clock customer support

- Convenient online submission

- Thorough peer review

- Inclusion in PubMed and all major indexing services

- Maximum visibility for your research

Submit your manuscript at www.biomedcentral.com/submit 